NASA Technical Memorandum 100753

\title{
Gravimetric Measurements of Materials Outgassing Applied to Graphite-Epoxy Laminates
}

J.J. Scialdone

December 1989

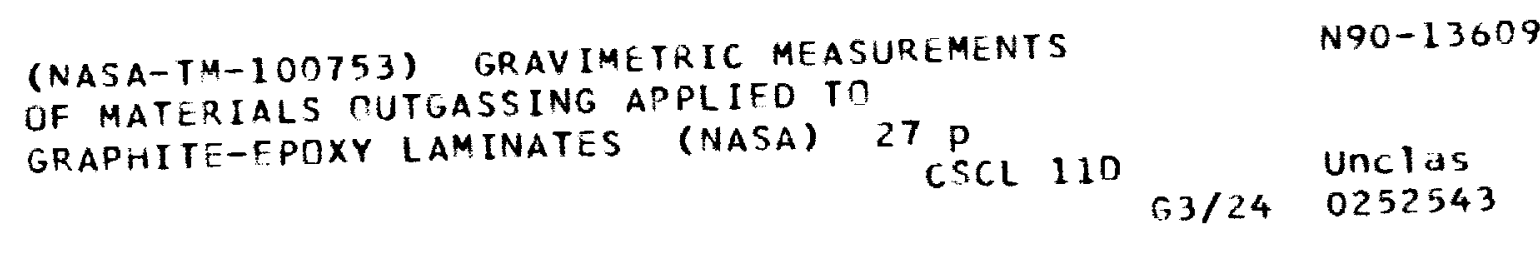


$-\ldots$

ra 
NASA Technical Memorandum 100753

\section{Gravimetric Measurements of Materials Outgassing Applied to Graphite-Epoxy Laminates}

J.J. Scialdone

Goddard Space Flight Center

Greenbelt, Maryland

\section{N/Sก \\ National Aeronautics and \\ Space Administration}

Goddard Space Flight Center

Greenbelt, MD 


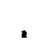

\section{E}




\title{
GRAVIMETRIC MEASUREMENTS OF MATERIALS OUTGASSING APPLIED TO GRAPHITE-EPOXY LAMINATES
}

\author{
John J. Scialdone \\ Goddard Space Flight Center \\ Greenbelt, $\mathrm{MD}$
}

\section{PREFACE}

The outgassing rates of two Graphite-Epoxy Laminates, American Cyanamide 985B-626 and HST-7B112, were obtained using a gravimetric method. The rates as a function of time and temperature were derived from the measurements of their mass losses at temperatures varying from $25^{\circ} \mathrm{C}$ to $150^{\circ} \mathrm{C}$ and for a time span of up to 400 hours in a vacuum. The data from those measurements were reduced to obtain the outgassing activation energies, the mass losses per unit mass or area, and the corresponding outgassing rates. The rates are expressed in closed form equations and are directly usable for modeling computations. The procedures to obtain these parameters are shown and may be used for the evaluation of other materials. The analysis can be carried out quite rapidly using a computer's algorithm.

The results of the tests and analyses show the following. The activation energies of the two materials are: $4630 \mathrm{cal} / \mathrm{mole}$ for the $985 \mathrm{~B}-626 \mathrm{material}$ and $4791 \mathrm{cal} / \mathrm{mole}$ for the HST-7B-112 sample \#10 Graphite Epoxy.

The outgassing rates of these materials are in the $10 \mathrm{E}-5 \mathrm{~g} / \mathrm{cm}^{2} \mathrm{hr}$ range and they decay according to a power of time of 0.60 at $25^{\circ} \mathrm{C}$, indicating that the outgassing process is mainly a diffusion at that temperature. At higher temperatures, these materials show a time decay approaching a power of one, which may be the result of several outgassing processes occurring sinultaneously, and/or the result of the change in heat of desorption as a function of the amount of material on the surface. A large amount, (30 to 40 percent of those rates) consists of water as shown by the mass spectrometer data and by the measured water regained by the material after outgassing at $125^{\circ} \mathrm{C}$ for 24 hours. Tests also showed that I month after that test, a repeated $125^{\circ} \mathrm{C}$. 24-hour test produced 
a total mass loss comparable to the water regained after the first test. The condensable material accumulated on the $25^{\circ} \mathrm{C}$ collector disk after the first ASTM-E595 test was 0.01 percent of the total mass and was not measurable after the second test, which occurred a month later.

The normalized mass losses versus time obtained from these tests have been compared to the discrete results obtained from the ASTM-E595 tests. The comparison provides general indications on the effects of temperature and time in relation to the ASTM test values obtained at $125^{\circ} \mathrm{C}$ for a 24 -hour test duration. 


\section{INTRODUCTION}

Contamination from materials outgassing, and from other molecular or particulate sources, can degrade the performance of an instrument or spacecraft. An understanding of the contaminant source, its transport, deposition, and effects on a surface and on the environment is of importance for the prediction, the mitigation of the contamination, and the expected degradation of the spacecraft's orbital environment. The degradation of an onboard system and of the surrounding environment due to molecular sources can be avoided or reduced by knowing the outgassing properties of the materials in the system. The effects of temperature and time on outgassing rates as well as the chemical nature of the outgassing must be known. A knowledge of these parameters, together with a proper shielding of the critical surfaces, the proper venting and directional dissipation of the outgassing into the environment, and the delayed exposure of outgassing materials to high temperature can all contribute to the avoidance and reduction of contaminant deposits on surfaces-and of the degradation of the surrounding environment.

In this paper, the outgassing of Graphite-Epoxy laminate bars used extensively in structures for space applications is measured using a gravimetric method. The material outgassing activation energy, and the outgassing rates as a function of time, surface area, and temperature are obtained by measuring the weight loss of the material in vacuum at various constant temperatures and as a function of time. These data provide a description of the outgassing rates versus time of the material at those temperatures as well as the energy of activation needed for its removal from a surface on which it may have deposited (if the deposited material was not affected by external sources of radiation.) The time dependence of the outgassing also provides indications of the mechanism of the outgassing, be it surface desorption, diffusion, permeation or a combination of those effects. These indicalions on the outgassing processes are helpful in finding ways to limit their gaseous releases. The lest data obtained in these measurements have been reduced, assuming that the outgassing is produced by at generalized first-order reaction kinctics modified to account for the several products comprising the outgassing. The outgassing results and the present approach are to be compared all a later (late fo the results obtained from other methods. $\Lambda$ comparison with the results obtained from llic $\Lambda$ STIM- 
E595 outgassing method provides additional understanding of those single, discrete results. The ASTM method (Ref. 1) indicates the percentage of weight loss and the percentage deposited on a collector at $25^{\circ} \mathrm{C}$ when the material under test has been exposed to $125^{\circ} \mathrm{C}$ in vacuum for 24 hours. The data from that test are easily obtained and extensively used. The screening of materials for space applications is based on those tests. The criteria for acceptance of a material are that it should lose less than 1 percent of its weight and produce less than 0.1 percent volatile condensable material when tested according to the ASTM test. The results using the present methods are expected to be compared at a later time to those obtained from a thermogravimetric analysis (TGA) which utilizes the temperature scanning of the material and the relative weight loss to derive the kinetic properties; i.e., activation energy, pre-exponent for activation, and order of the outgassing reaction process. The TGA method is quite simple and rapid, offering significant saving of time and effort if it can be reliably used and interpreted.

It is also intended at a later date to perform a comparison using simultaneously the present weight loss method and the method employing a Quartz Crystal Microbalance (QCM). The QCM method measures the accretion of outgassing products on a vibrating crystal held at chosen temperatures. That method has the advantage of providing indications for the identification of the accreted products. The temperature of the Quartz Crystal is varied to release or accrete the deposited material and infer from those temperatures the nature of the condensate.

\section{IEXPERIMLNTAL PROCLDURE}

Two types of graphite-epoxy laminates were tested, at 10E-6 torr pressure. and temperatures of 25,50 , 100. 125 and $150^{\circ} \mathrm{C}$ to measure their weight losses versus time. The measurements were carried out using an Ainsworth Recording Vacum Balance. The balance, which hals a capacity of 100 g. has a sensitivity of $0.1 \mathrm{mg}$, and the readability on the Bristol strip chat is also $0.1 \mathrm{mg}$. The specimen weight loss is atutomatically recorded on the strip charts which also record the temperature. The tempralure of the specimen an be varied in increments of $5^{\circ} \mathrm{C}$. Thi vacuum chamber in which the sample is inserted and heated is 3 inches in diameter and is 20 inches long. The initial operation consists of weighing the simple before being inserted in the balane and adjusting the balance accordingly. 
The graphite-epoxy samples, provided by the American Cyanamide Co. were: CYCOM HST-7, Batch 112, which will be referred to here as sample \#10; and CYCOM 985, Batch 26, referred to as sample \#4.

The HST-7 sample \#10 is an epoxy-laminated material for use as a structural composite where high toughness and impact properties are required. It is a combination of two layers. A high-modulus resin is used on the graphite fiber. A separate high-strain resin layer is applied to one side of the graphite prepreg to provide a stiffness to the system. Optimum properties are achieved by curing under a pressure of $100 \mathrm{psi}$ at $177^{\circ} \mathrm{C}$ for 2 hours. The resin content is given as $45.9 \%$; the aereal weight as $146.1 \mathrm{~g} / \mathrm{m}^{2}$ and is specified to have $1 \%$ maximum volatile components. The sample used for this test was $1.9985 "$ wide, 0.1230 " thick and had an initial mass of 2.888 grams.

The CYCOM-985 sample \#4 is a graphite-epoxy composite for applications where a good balance between performance and processing is required. It has a resin content of $33.9 \%$, an aereal graphite weight of $144 \mathrm{~g} / \mathrm{m}^{2}$, and a volatile component of $0.22 \%$. The weave is specified as a $12-1 / 2 \mathrm{X}$ 12-1/2 plain which will consist of 14 plies. The dimensions of the test sample were 1.9915 "long. $0.5000 "$ wide, $0.0920 "$ thick and the initial mass was 2.0631 grams.

The mass loss of the sample was recorded continuously and typed in a Lotus 1-2-3 file. The losses during the initial 2.5 hours of each test run were sampled every 15 minutes. After the initial 2.5 hours of rapid mass changing, the sampling was done every 30 minutes.

The data obtained from the tests are shown in Figures 1 and 2 for the samples \#10 and \#4, respectively. The mass losses have been normalized to the mass loss of the sample taken after 24 hours at 125\% $\mathrm{C}$. This was done to correlate with the mass losses measured using the ASTM-E595 fest method and to gencralize the tests. The total mass losses and other pertinent data on the sample have beco shown in the ligures. liguress 3 and 4 show the log to base 10 of the initial mass loss rales, al $1=0$ versus $/ / T$ where $T(K)$ represent the isothermal outgassing temperatures of the simples. These ane Arrhenius plots of the outgassing reation rates shown in terms of log to base 10) rather than log to base $\therefore$, which are repuired for the analysis of the data and the derivation of 
the activation energy and of the pre-exponent term of the Arrhenius equation. The slopes of the curves indicate the activation energies required for the outgassing. The intersections of the curves with the $\mathrm{Y}$ axis showing the outgassing rates represent the pre-exponential term in the Arrhenius expression for the reaction rates. Additional characterizations of the graphite-epoxy material have been provided. The mass spectrum of sample \#4, laminate $985 \mathrm{~B}-626$, and the results of the ASTME595 for both samples are enclosed in the appendix.

Theory

Rate of Mass Loss and Activation Energy Assuming that the outgassing may be represented by a first-order reaction kinetics within the range of temperatures under consideration (refs. 2 and 3 ), the rate of mass loss is $\mathrm{dm} / \mathrm{dt}=-\mathrm{km}$, where $m(g)$ is the mass and $k=A$ exp $-E / R T$ is the Arrhenius expression relating the reaction constant $k$ to the activation energy $\mathrm{E}$, (cal/mole) required for outgassing, the temperature $T(K)$; the frequency factor $A(l / s)$, and $R(c a l / m o l e / K)$ the gas constant. The constant $k$ can also be written for convenience as $\mathrm{k}=1 / \tau$, where $\tau=\tau_{0} \exp \mathrm{E} / \mathrm{RT}$ and the mass loss rate is then

$$
\mathrm{dm} / \mathrm{dt}=-\mathrm{m} / \tau
$$

The integration of this for $\mathrm{m}=\mathrm{m}_{0}$, when $\mathrm{t}=\mathrm{o}$, indicates that the mass remaining as a function of time is given by

$$
m=m_{0} \exp -t / \tau
$$

and the mass loss comparable to the data reported in Figures 1 and 2 is

$$
m_{0}-m=m_{0}(1-\exp -t / \tau)
$$

In Figures 1 and 2 , the value of $\left(m_{0},-m\right)$, as in this last expression, has been normalized by llke loss $\left(m_{r}\right)$ produced by the material after 24 hours at $125^{\circ}\left(\mathrm{C}\right.$. This normalized loss $\left(m_{0}-m\right) / m_{1}$ is shown on the plot, and the units along the $Y$ axis are $(g / g)$. The loss can also be expressed in terms of the area in the sample $\left(\mathrm{g} / \mathrm{cm}^{2}\right)$ when the loss results are expressed in terms of llic sample surface areas. 
The rate of mass change from the above is representable in any of the following forms:

$$
\mathrm{dm} / \mathrm{dt}=-\mathrm{km}=-\mathrm{m} / \tau=\mathrm{m}_{\mathrm{o}} / \tau \exp -\mathrm{t} / \tau=-\mathrm{mA} \exp -\mathrm{E} / \mathrm{RT}
$$

Taking the natural log of both sides of the above expression after dividing by $\mathrm{m}$, one gets

$$
\ln (1 / \mathrm{m} \mathrm{dm} / \mathrm{dt})=-\ln \mathrm{A}-\mathrm{E} / \mathrm{R}(1 / \mathrm{T})
$$

The plot of $\ln 1 / \mathrm{mdm} / \mathrm{dt}$ versus $1 / \mathrm{T}$ indicates the slope of $1 / \mathrm{T}$ which is $\mathrm{E} / \mathrm{R}$ and the value of the frequency factor $A$ which is given by the intersection of the curve with the $\mathrm{Y}$ axis.

Figures 3 and 4 show the plot of the $\log \left(1 / m_{r}\left(m_{0}-m / t-t_{0}\right)\right.$ versus $1 / T$ taken from the data in Figures 1 and 2. The appropriate change from $\log$ to base 10 to $\ln$ provides the value of $\mathrm{E} / \mathrm{R}$.

The equivalent activation energy can also be estimated by comparing the outgassing rates at the same time for two outgassing temperatures, $\mathrm{T}_{1}$ and $\mathrm{T}_{2}$, assuming the difference in temperature is small. In fact, from Eq. 4, the rates are related by the Arrhenius relation:

$$
\left.\left|\mathrm{dm} / \mathrm{dt}_{\mathrm{T}_{1}} /\right| \frac{\mathrm{dm}}{\mathrm{dt}}\right|_{\mathrm{T}_{2}}=\exp \mathrm{E} / \mathrm{R}\left(1 / \mathrm{T}_{2}-1 / \mathrm{T}_{1}\right)
$$

This assumes that $\mathrm{E}$ remains constant within the range of temperatures being considered and does not change as a function of the mass loss.

The plots in Figures 1 and 2 do not show the exponential time dependence indicated by Eq. 3, nor do they show the time dependence for the rate of outgassing indicated by Eq. 4 . This time dependence is, in general, verified in many cases of material outgassing, because the outgassing consists of the release of different concentrations of materials following various processes and the firstorder reaction kinetics is not applicable (Refs. 4 and 5). The actual outgassing rates as obtaincel from Figures 1 and 2 are shown in Figures 5 and 6 . These were determined by plotling on loglog coordinates, the rate of change of masses,

$$
\left(m_{n-1}-m_{n}\right) /\left(t_{n+1}-t_{11}\right) 1 / \Lambda
$$


versus time. The slope of the plotted curve and the intersection with the $Y$ axis show that the outgassing rates are expressible by the function

$$
\mathrm{dm} / \mathrm{dt}(1 / \mathrm{A})=\mathrm{B} / \mathrm{t}^{\mathrm{n}}
$$

The constant $B$ is given by the intersection with the $Y$ axis and it includes the effect of the temperature on the outgassing, the activation energy, and the units used for mass and time. Its value includes the Arrhenius factor A exp - E/RT which can be obtained in a process of comparison as shown by Eq. 5. The exponent $\mathrm{n}$ indicates how the rate changes with time. By a process of association with the rate change with time for known physical processes, one can obtain an indication of the prevailing process involved in that particular outgassing: i.e., diffusion. surface physical or chemical desorption, permeation, sublimation or a combination of those processes (Ref. 5). In general, the experimental data on outgassing indicates that for fixed-material temperatures and for a considerable length of time, the outgassing rates are expressible by

$$
\mathrm{dm} / \mathrm{dt}=\mathrm{B} / \mathrm{t}^{\mathrm{n}} \approx(\mathrm{A} \exp -\mathrm{E} / \mathrm{RT}) \mathrm{t}^{-\mathrm{n}}
$$

where $A, T$, and $E$ are parameters included in the value of $B$.

\section{Data Reduction}

The normalized mass losses shown in Figures 1 and 2 modified by the appropriate parameters, provide the mass-loss-per-unit mass $\left(m_{0}-m / m_{r}\right) m_{r} / m_{0}$ and the mass-loss-per-unit area versus time and as a function of the outgassing temperature. The masses of the samples and the surface areas were measured at room temperature with $50 \%$ relative humidity. The log of the normalized initial mass loss rates, $\log \left(m_{0},-m / m_{r} / t-t_{0}\right)$ versus the inverse of the absolute temperature of the outgassing $(1 / \mathrm{T})$, is showl in figures 3 and 4 . These are the plots of the log to base 10 of Eq. 4 . However, the activation colergies $\mathrm{I}$ : and the frequency fictor $A$ must be obtained by plotting the data in terms of the natural log. The value $E / R$ (intercept on $X$ ) and the $A$ (intercept on $Y$ ) shown on the figures, have been changed to the appropriate In. The results for the activation energy and the fre(fuency fictor are 46.30 .27 (cal/mols) and $37.94\left(\mathrm{hr}^{-1}\right)$, respectively, for sample \#4 and $4791.7 \mathrm{cal} /$ 
mole and $46.049\left(\mathrm{hr}^{-1}\right)$ for sample $\# 10$. Regression analyses on these results show errors of $3.5 \%$ for sample \#4 and $6.9 \%$ for sample \#10, for the activation energies; and 2.9 and $4.0 \%$ for the frequency factors. The activation energies of sample \#4 obtained using Eq. 6, and the rates of mass loss shown in Figure 1 when measured in the interval of time from 20 hours to 30 hours, and for temperature $(\mathrm{K})$ ratios of $323 / 298,373 / 298,398 / 298,398 / 373$, varied from $3404 \mathrm{cal} / \mathrm{mole}$ for the ratio of $273 / 298$ to $4994 \mathrm{cal} / \mathrm{mole}$ for the $398 / 373$ ratio. The average activation energy was $4070 \mathrm{cal} /$ mole. This average value is $88 \%$ of $E=4630$ obtained from the initial rates of mass loss.

The outgassing rates per-unit-area $1 / \mathrm{A} \mathrm{dm} / \mathrm{dt}$, obtained from Figures 1 and 2 plotted as a function of time and for different isothermal outgassing rates are shown in Figures 5 and 6 . The data are plotted in $\log -\log$ coordinates to provide, as indicated by $\mathrm{Eq}$. 8, the constant $\mathrm{B}$ and the exponent $\mathrm{n}$ for the time. The errors for the $\mathrm{n}$ values were less than $5 \%$ and for the constant $\mathrm{B}$, about $20 \%$. The equivalent errors for sample \#10 were less than $3.4 \%$ for the $\mathrm{n}$ and about $16 \%$ for B. Table 1 shows the values obtained from those plots and the relative equations for outgassing at the various temperatures.

The outgassing rates of the graphite-epoxy material, as found here, are comparable to the results for similar materials indicated in the literature (Ref. 6). The material exhibits considerable outgassing. The test data in the appendix provide some explanation for this behavior. The mass spectrometer fragmentation of the material at $290^{\circ} \mathrm{C}$ shows the spectrum with major picks at $243,93,106,108$, 77 and $65 \mathrm{~m} / \mathrm{c}$. These are representative of aromatic epoxy compounds that are amino cured. The mass spectrometer detected no $(<1 \%)$ outgassing at temperatures less than $200^{\circ} \mathrm{C}$. The ASTM tests indicated that the water regained by the two samples at $50 \%$ R.H., and $25^{\circ} \mathrm{C}$ was $0.31 \%$ for sample \#4 and $0.26 \%$ for sample \#10. A comparison of these values to those of the total mass losses indicates that a considerable amount of the outgassing. on the order of $30-40 \%$, is water. Also, the condensable amount of the totil loss at $25^{\circ} \mathrm{C}$ is only $0.01 \%$

\section{RISULTS AND CONCLUSIONS}

The outgassing rates of two graphite-epoxy laminates, American Cyanamide $985 \mathrm{~B}-626$ and HST-7B- 
112, were obtained using a gravimetric method. The rates as a function of time and temperature were derived from the measurements of their mass losses at temperatures varying from $25^{\circ} \mathrm{C}$ to $150^{\circ} \mathrm{C}$ and for a span time of up to 400 hours in vacuum. The data from those measurements were reduced to obtain the outgassing activation energies, the mass losses per unit mass or area, and the corresponding outgassing rates. The rates are expressed in closed-form equations and are directly usable for modeling computations. The procedures to obtain these parameters have been shown and may be used for the evaluation of other materials. The analysis can be carried out quite rapidly using a computer's algorithm.

The results of the tests and analyses show the following:

- The activation energies of the two materials are: $4630 \mathrm{cal} / \mathrm{mole}$ for the $985 \mathrm{~B}-626$ material and $4791 \mathrm{cal} / \mathrm{mole}$ for the HST-7B-112 sample \#10 graphite-epoxy. They show the limited amount of energy needed to affect the outgassing.

- The outgassing rates of these materials are in the $10 \mathrm{E}-5 \mathrm{~g} / \mathrm{cm}^{2} \mathrm{hr}$ range and decay according to a power of time of 0.60 at $25^{\circ} \mathrm{C}$. This rate decay indicates that the outgassing process is mainly a diffusion at that temperature. At higher temperatures, these materials show a time decay approaching a power of one. This behavior, theoretically justifiable, occurs when the outgassing is the result of several processes occurring simultaneously, including the change in heat of desorption as a function of the amount of material on the surface.

- The analysis shows that the outgassing does not follow a first-order reaction kinetics but rather, follows a higher order.

- The outgassing rates are relatively high. However, $30-40 \%$ of those rates consist of water as shown by the mass spectrometer data and the measured water regained by the material after outgassing at $125^{\circ} \mathrm{C}$ for 24 hours. Tests have also shown that 1 month after that test, a repealled $125^{\circ} \mathrm{C}, 24$-hour test produces a total mass loss comparable to the water regained alter the lirst test. 
- The condensable material accumulated on the $25^{\circ} \mathrm{C}$ collector disk after the first ASTM test was $0.01 \%$ of the total mass and not measurable after the second test, a month after.

- The data obtained from these tests can be used for several purposes:

The normalized mass losses versus time can be compared to the discrete results obtained from the ASTM-E595 test which are used extensively for acceptability of materials for space application. The comparison can provide general indications on the effects of temperature and time in relation to the values obtained at a $125^{\circ} \mathrm{C}, 24$-hour test.

- The activation energy data allow one to estimate the effect of temperature on outgassing and the effect that the temperature will have on preventing and removing contaminant deposits from a surface, provided that radiation and accumulation of other materials have not changed the nature of the deposit.

- The closed-form expressions for the outgassing rates permit one to estimate, in conjunction with other data, the internal pressure in a system and the density conditions produced in the surrounding environment as a function of time. Certain acceptable conditions of pressure and density can be established in this manner.

- Finally, the gravimetric method for obtaining the needed outgassing data has been shown. The method is relatively simple and requires less manipulation of the data than other methods.

\section{Acknowledgment}

The author acknowledges the help of Mr. R. Hunkeler who made weight loss measurements, Ms. J. Kestner who digitized and plotted the data, and Mr. J. Ming for help in the data reduction. 
Table 1

Sample \#4 Am. CY 985-B - 626 Graphite - Epoxy Laminate

$$
\left(\mathrm{m}_{\mathrm{r}}=11.2 \mathrm{E}-3 \mathrm{~g}, \mathrm{~A}=6.24 \mathrm{~cm}^{2}, \mathrm{~m}_{\mathrm{o}}=2.0631 \mathrm{~g}\right)
$$

\begin{tabular}{|c|c|c|c|c|c|c|c|}
\hline $\begin{array}{l}\text { Temp. } \\
\left({ }^{\circ} \mathrm{C}\right)\end{array}$ & $\begin{array}{l}\text { Slope } \\
\mathrm{n}\end{array}$ & $\log (\mathrm{dm} / \mathrm{dt} \quad 1 / \mathrm{A})$ & \multicolumn{2}{|c|}{$\begin{array}{c}1 / \mathrm{Adm} / \mathrm{dt} \\
\left(\mathrm{mg} / \mathrm{cm}^{2} \mathrm{hr}\right)\end{array}$} & \multicolumn{3}{|c|}{$\begin{array}{l}\text { Outgass. rate } \\
\mathrm{g} / \mathrm{cm}^{2} / \mathrm{hr}\end{array}$} \\
\hline 25 & -0.6204 & -1.36432 & 4.325 & $E-2$ & 4.325 & $E-5$ & $t^{-.6204}$ \\
\hline 50 & -0.56169 & -1.14980 & 7.095 & $\mathrm{E}-2$ & 7.095 & $E-5$ & $\mathrm{t}^{-.561}$ \\
\hline 100 & -0.72912 & -0.69611 & 2.013 & $E-1$ & 2.013 & $E-4$ & $\mathrm{t}^{-.729}$ \\
\hline 125 & -0.8612 & -0.537 & 2.904 & $E-1$ & 2.013 & $E-4$ & $t^{-.8612}$ \\
\hline 150 & -.97099 & -0.34138 & 4.560 & $E-1$ & 4.56 & $E-4$ & $t^{-.970}$ \\
\hline
\end{tabular}

Sample \#10, Am. CY HST-7B-112 Graphite - Epoxy Laminate

$$
\left(\mathrm{m}_{1}=15.4 \mathrm{E}-3 \mathrm{~g}, \mathrm{~A}=6.74 \mathrm{~cm}^{2}, \mathrm{~m}_{0}=2.888 \mathrm{~g}\right)
$$

\begin{tabular}{|c|c|c|c|c|c|c|c|}
\hline $\begin{array}{l}\text { Temp. } \\
\left({ }^{\circ} \mathrm{C}\right)\end{array}$ & $\begin{array}{l}\text { Slope } \\
\mathrm{n}\end{array}$ & $\log (\mathrm{dm} / \mathrm{dt} \quad 1 / \mathrm{A})$ & $\begin{array}{r}1 \\
(\mathrm{mg}\end{array}$ & $\begin{array}{l}\mathrm{dm} / \mathrm{dt} \\
\left.\mathrm{m}^{2} / \mathrm{hr}\right)\end{array}$ & \multicolumn{3}{|c|}{$\begin{array}{l}\text { Outgass. rate } \\
\left(\mathrm{g} / \mathrm{cm}^{2} / \mathrm{hr}\right)\end{array}$} \\
\hline 25 & - & - & - & & $\ldots$ & & \\
\hline 50 & -0.5986 & -1.19956 & 6.32 & $\mathrm{E}-2$ & 6.32 & $E-5$ & $t^{-.598}$ \\
\hline 75 & -0.6445 & -0.89015 & 1.28 & E-I & 1.28 & $\mathrm{E}-4$ & $t^{-644}$ \\
\hline 100 & -0.69871 & -0.616 .53 & 2.42 & $E-1$ & 2.42 & $E:-4$ & $t^{-.616}$ \\
\hline 125 & -0.83342 & -0.42813 & 3.73 & $1:-1$ & 3.7 .3 & $1:-4$ & $\mathrm{t}^{-8.83}$ \\
\hline 150 & -0.96452 & -0.309 .34 & 4.90 & $1:-1$ & 4.90 & $1:-4$ & $t^{-.90 t}$ \\
\hline
\end{tabular}

NOTIS:

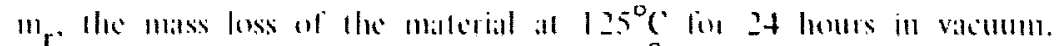

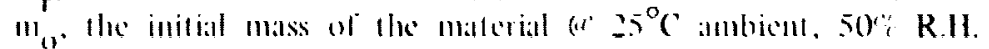

1. Time (III).

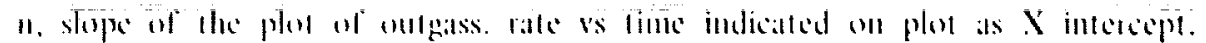

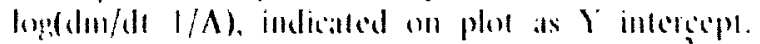

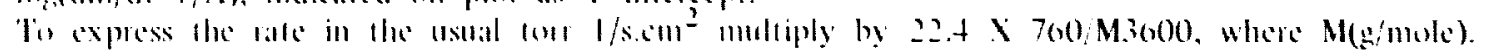




\section{REFERENCES}

1. Campbell, W. A., R. S. Marriott and J. J. Park, "An Outgassing Data Compilation of Spacecraft Materials," NASA RP 1124, August 1987.

2. Getman, F. G. and F. Daniels, Outlines of Theoretical Chemistry, 7th ed., 1945. John Wiley \& Sons, New York, NY.

3. Scialdone, J. J. "Characterization of the Outgassing of Spacecraft Materials," Proceedings of SPIE, the International Society of Optical Engineering, Vol. 287, Shuttle Optical Environment. April 23-24, 1981, Washington, D.C.

4. Dayton, B. B. "Relations Between Size of Vacuum Chamber Outgassing Rate and Required Pumping Speed," 6th National Symposium on Vacuum Tech. Trans., Pergamon Press. NY, 1959.

5. Schram, A. "La Desorption Sous Vide," Le Vide, No. 103, 1963.

6. Scialdone, J. J. "An Estimate of the Outgassing of Space Payloads." Jl. of Spacecraft \& Rockets, Vol. 23, No. 4, Jul-Aug 1986. pg. 373. 


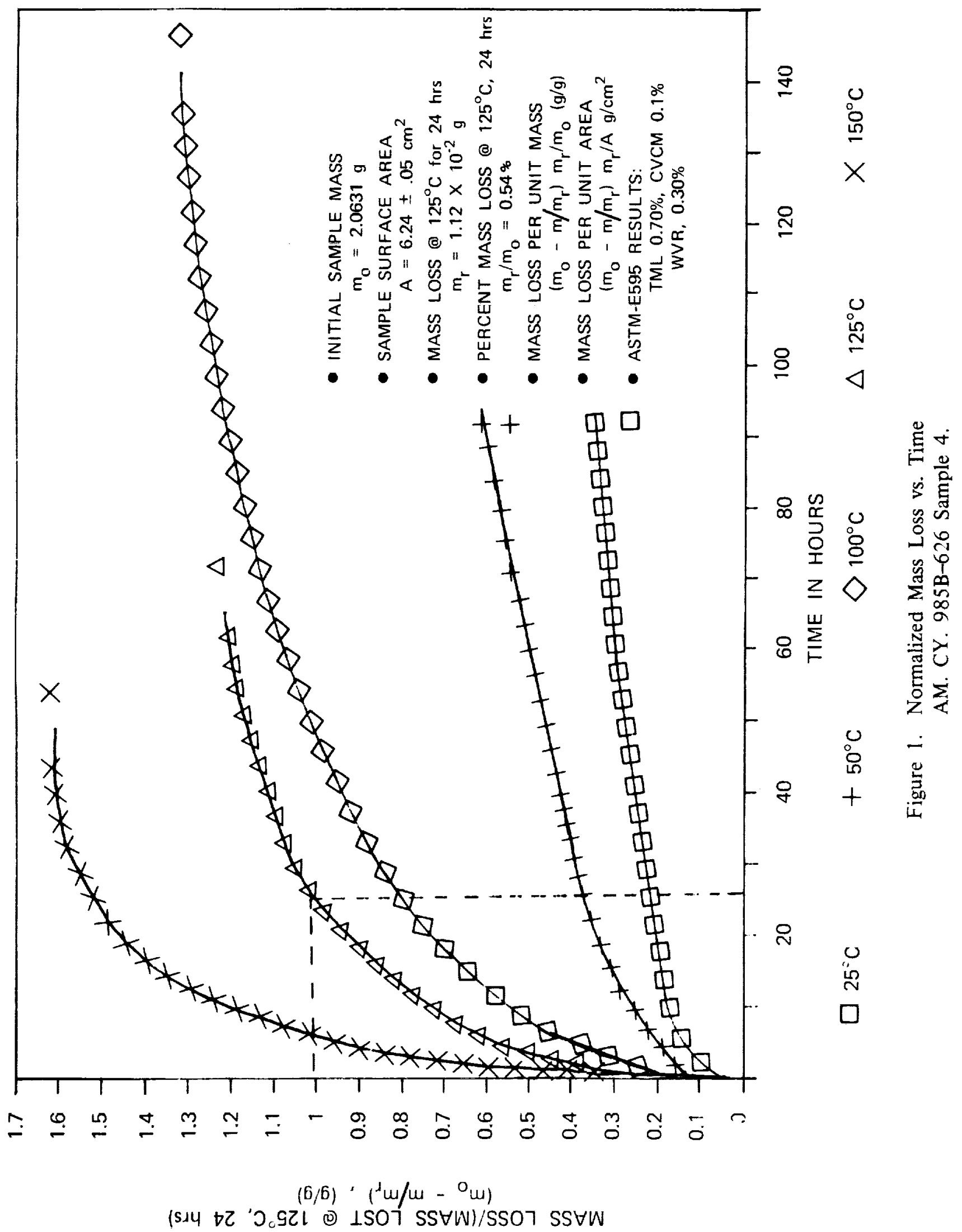




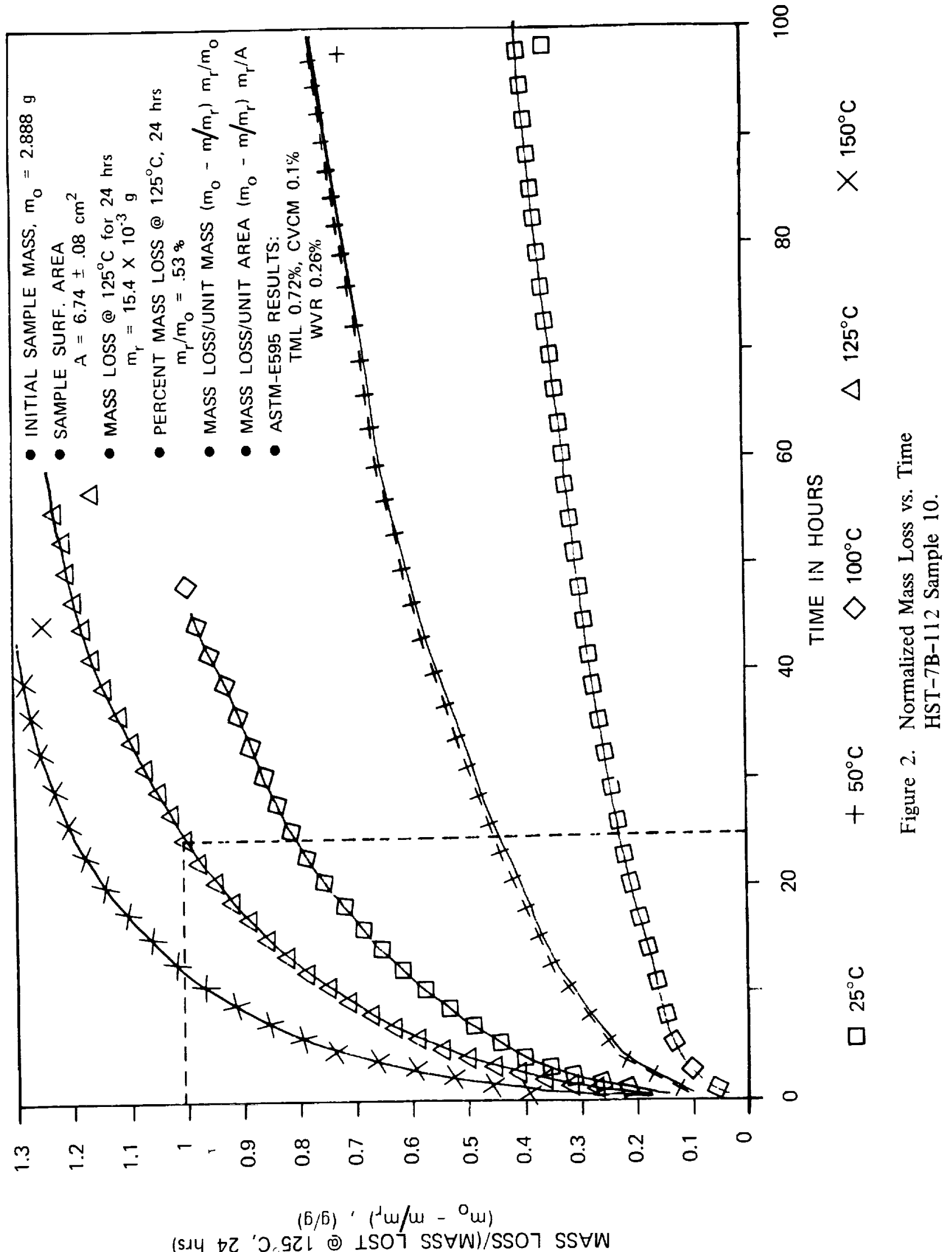




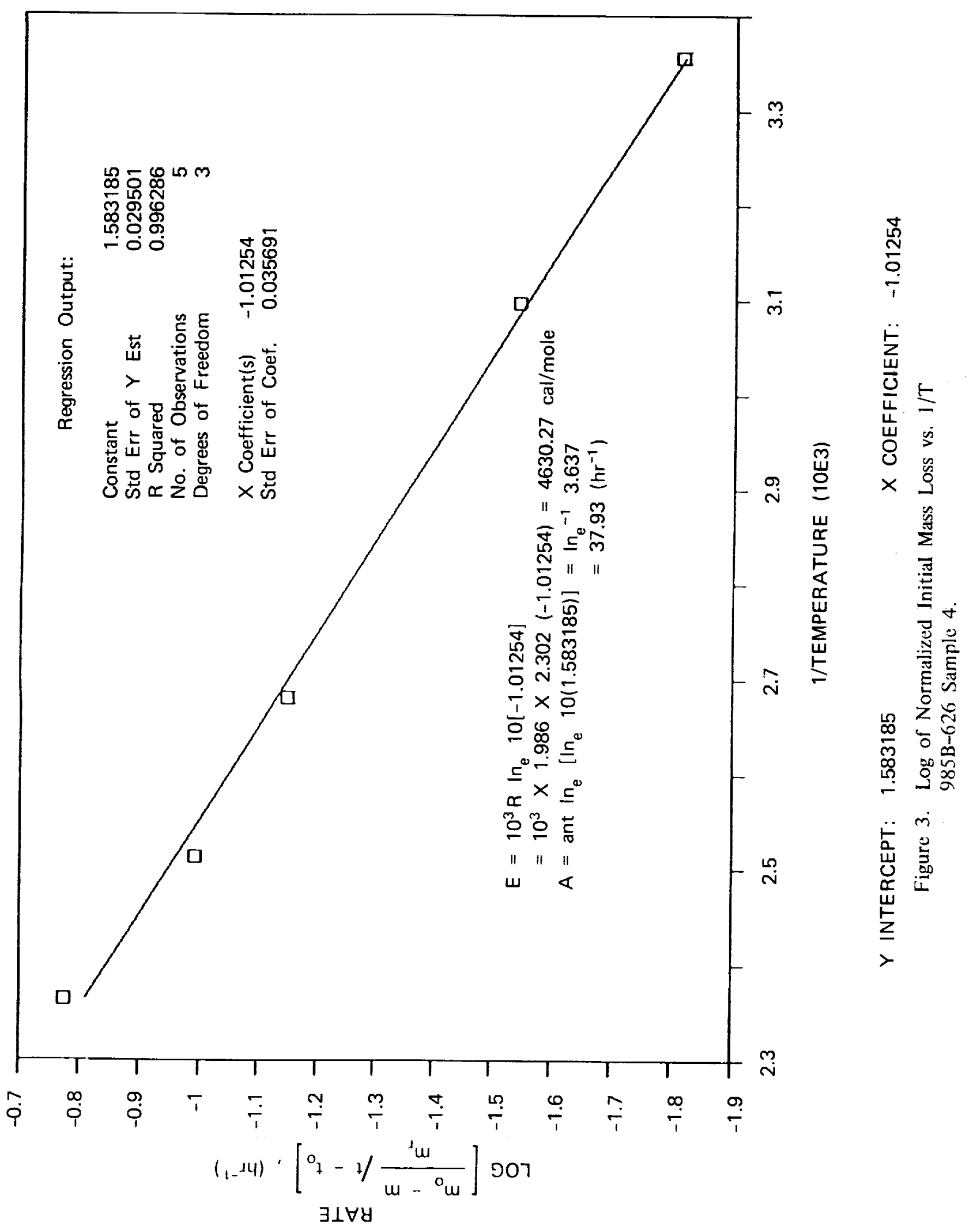




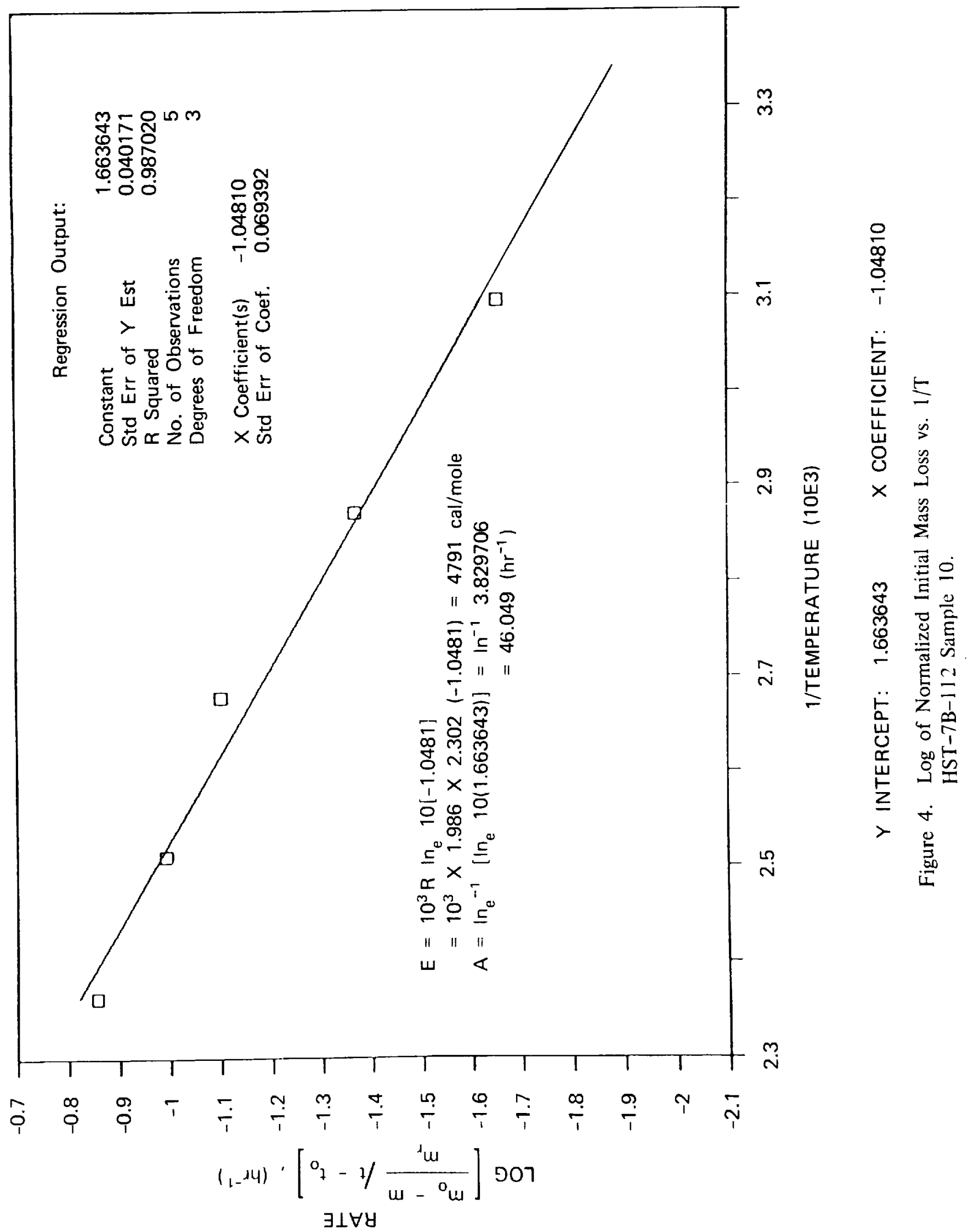




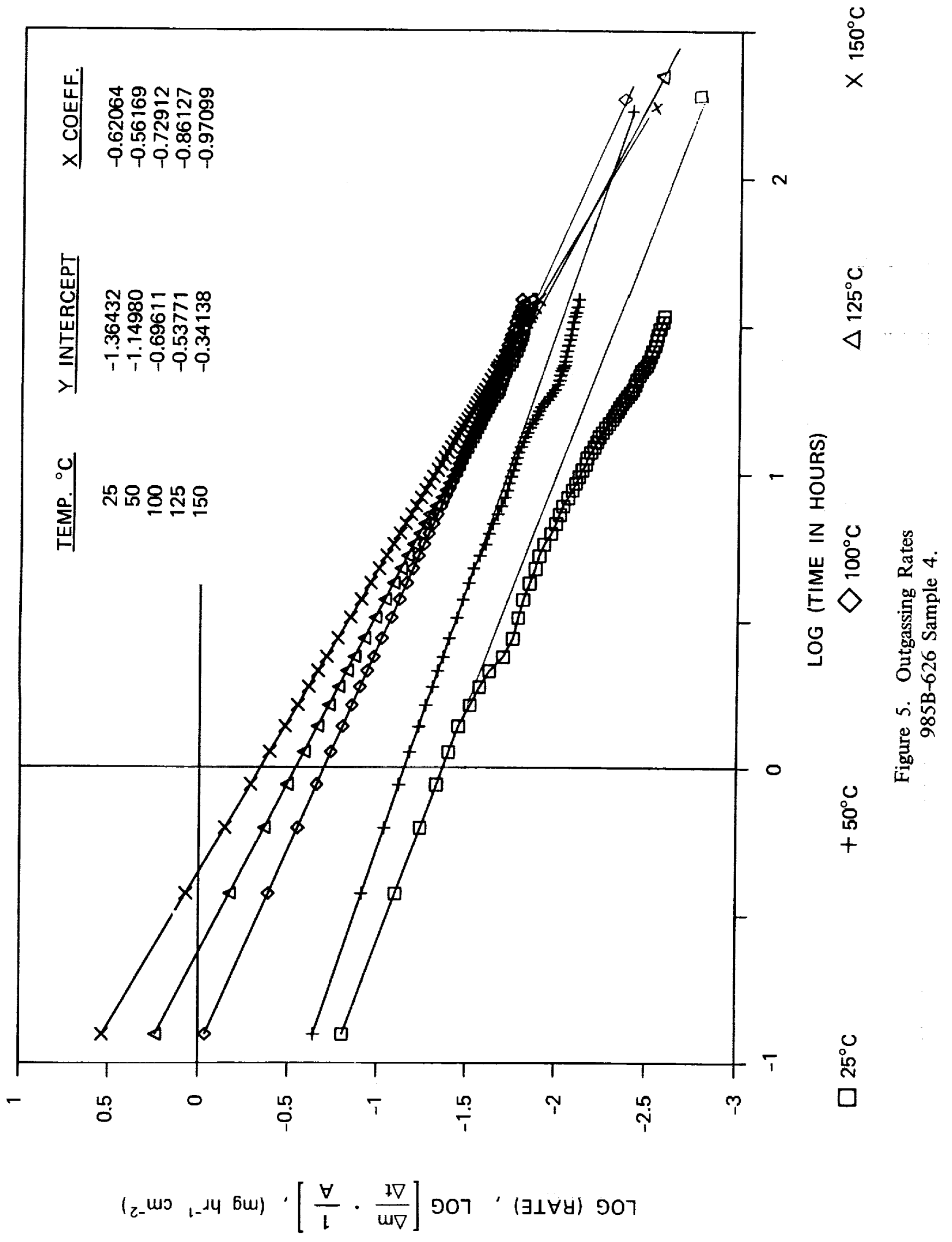




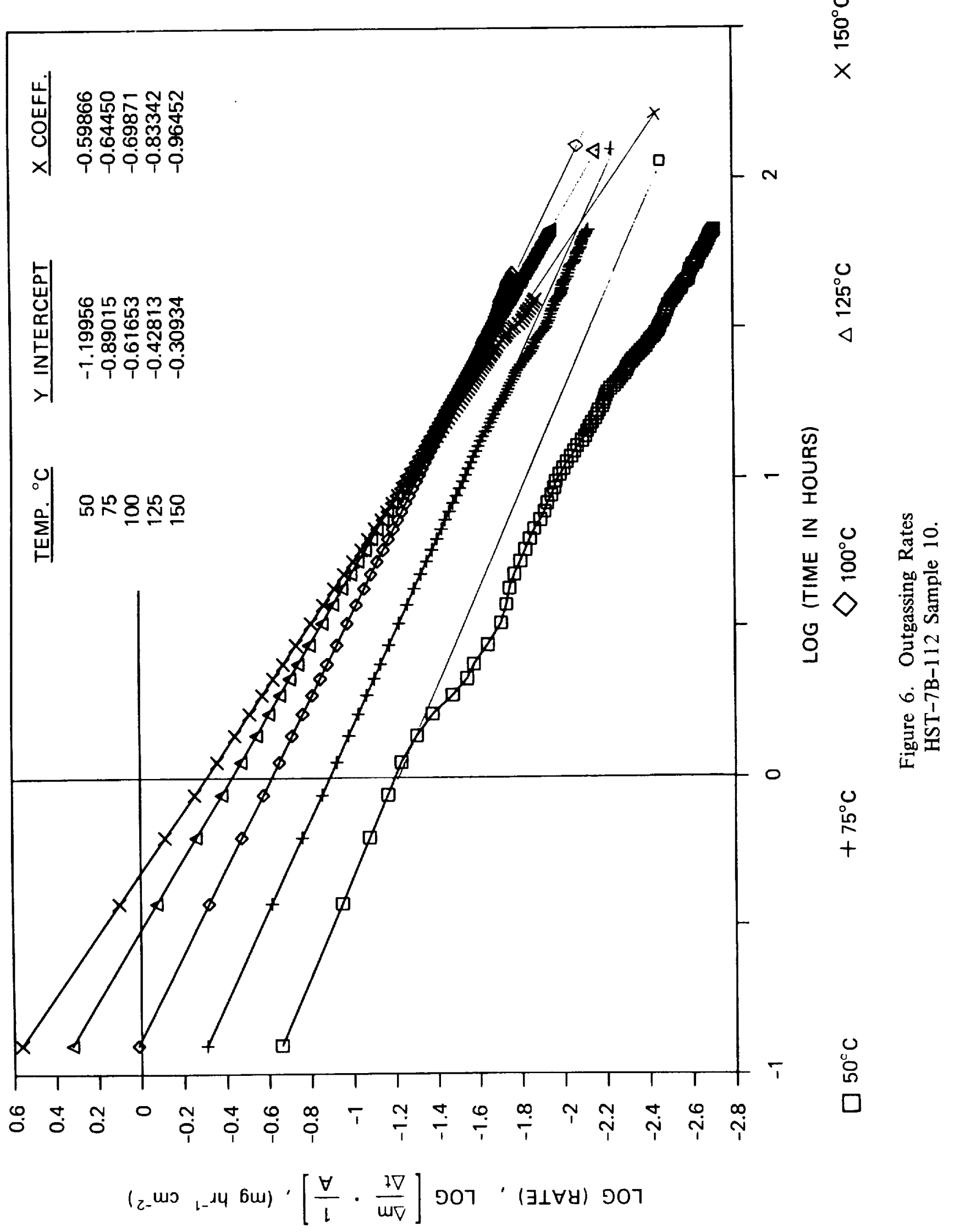


MICRO VCM TEST REQUEST AND DATA SHEET

(Requestor please read, then furnish all inforaation above asterisks.)

Requested by Soialdoule phone_pate 2-5-8E

Material Identification (product nae, nueber, description, classification, etcl

lavinate epoxy/sraphite $983 \overline{3}$ - 6.26

Kanulacturer of Material (Nace, City and State Adoress)

Material application lgeneral usage, i.e. adhesive, coating, potting, etc.l_Lallwivide

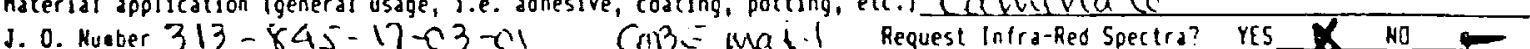

Indicate here all processing required by 6SFC Katerials personnel. Include the recipe, cure(s), and special instructions to be perforaed.

If aderial is to be tested in the "as received" condition, without further processing required, indicate in full, past history, recipe, curelgh, post zurelsi, nowenclature of components, etc.

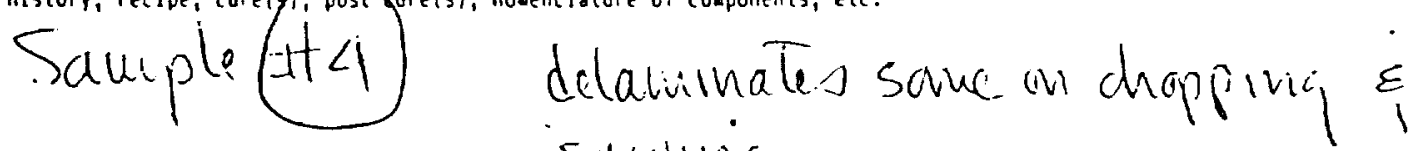
suwivg

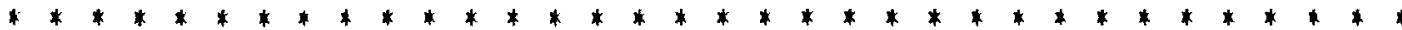

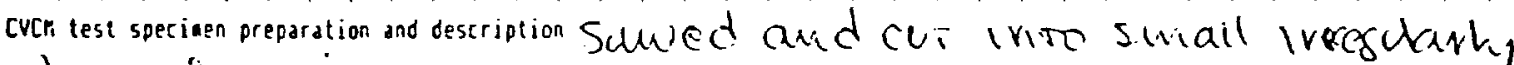
slagia pices

Bar position-[uCn Jest Hueber..............

Init ass, holder and specienn, ga.........

hass of holder, ge.......................

Init speciaen ass $\mathbf{S O}$ zRH, gE.........

hass after 50 zRH re-sosk, ga...........

Final ass, holder speciaen, ge..........

Tota! esss loss, speciaen, ge..............

Per-tent Inl, speciaen....................

Average value inti

Jotal ass, mater vapor regain, qa........

Per-cent water vapor regain.................

Average value KVR $S D$ IRH

Findl edss, collector, ga.................

Initial edss, collector, ga...............

Collected adss - Cren, ga..................

Per-cent cuck.............................

Average value $\mathrm{CVCH}$
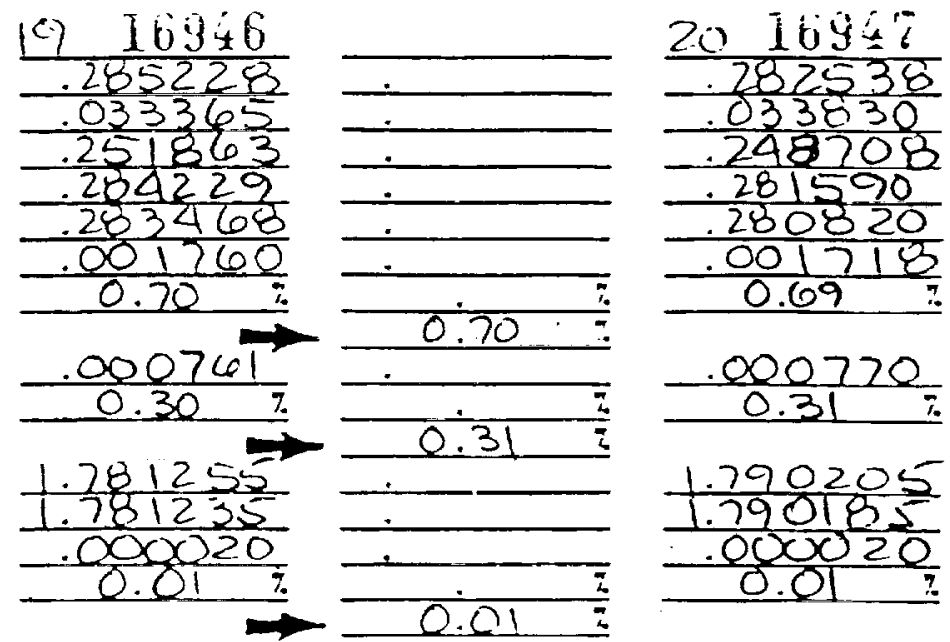

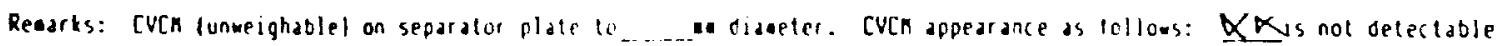
on collector plates: splotchy:

thin:

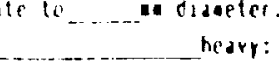
partially opaque: opdque: ealte:

color: seooth: seoky: pistorls ere rensparent: interterence ercess: Deposil covers I of collector dises: liquid runs in

specieen appearance atter test: no wesh he a hanige.-

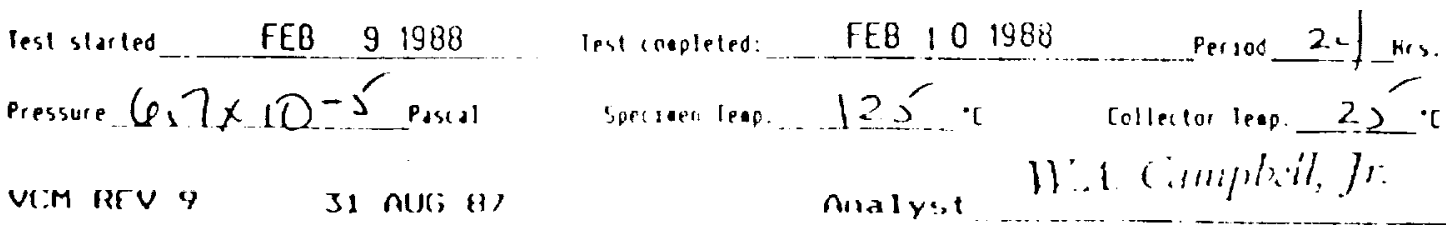

A-1. Sample 4, 985B-020 (\#16946). 
MICRO VCM TEST REQUEST AND DATA SHEET

(Requestor please read, thea furnish all inforaation above asterists.)

Requested or Scialdone. Phone Date Aaterial Identification (product nace, pueber, description, classification, elc)
Lavimate.
epory/graphite
$985 B-626$

nanulacturer of Material (Nane, City and State Address)

naterial application (general usage, i.e. adhesive, coating, potting, etc.)_tawilinats

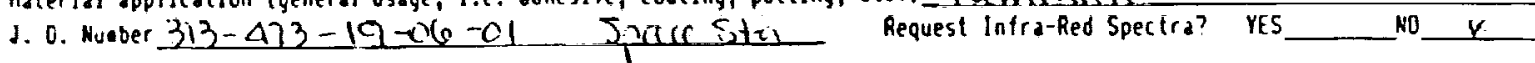

Indicate here all processing required by GSFC Materials personnel. Include the recipe, cure(s), and special instructions to be pertoraed.

$$
\begin{aligned}
& \text { Revin od asc } 16940 \text { Diplicatas } \\
& \text { pofirions Fela \& } 20
\end{aligned}
$$

If eaterial is to be tested in the "as received" condition, mithout further processing required, indicate in full, past history, recipe, cure(s), post cure(s), noaenclature of coeponents, etc.

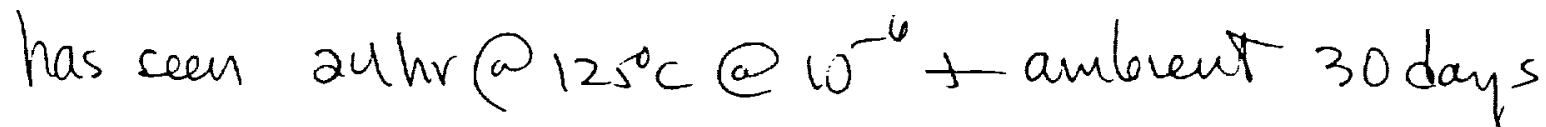

* * * * * * * * * ******************************* cucr test speciaen preparation and description small iregglarhy shaped peces placed un 6003
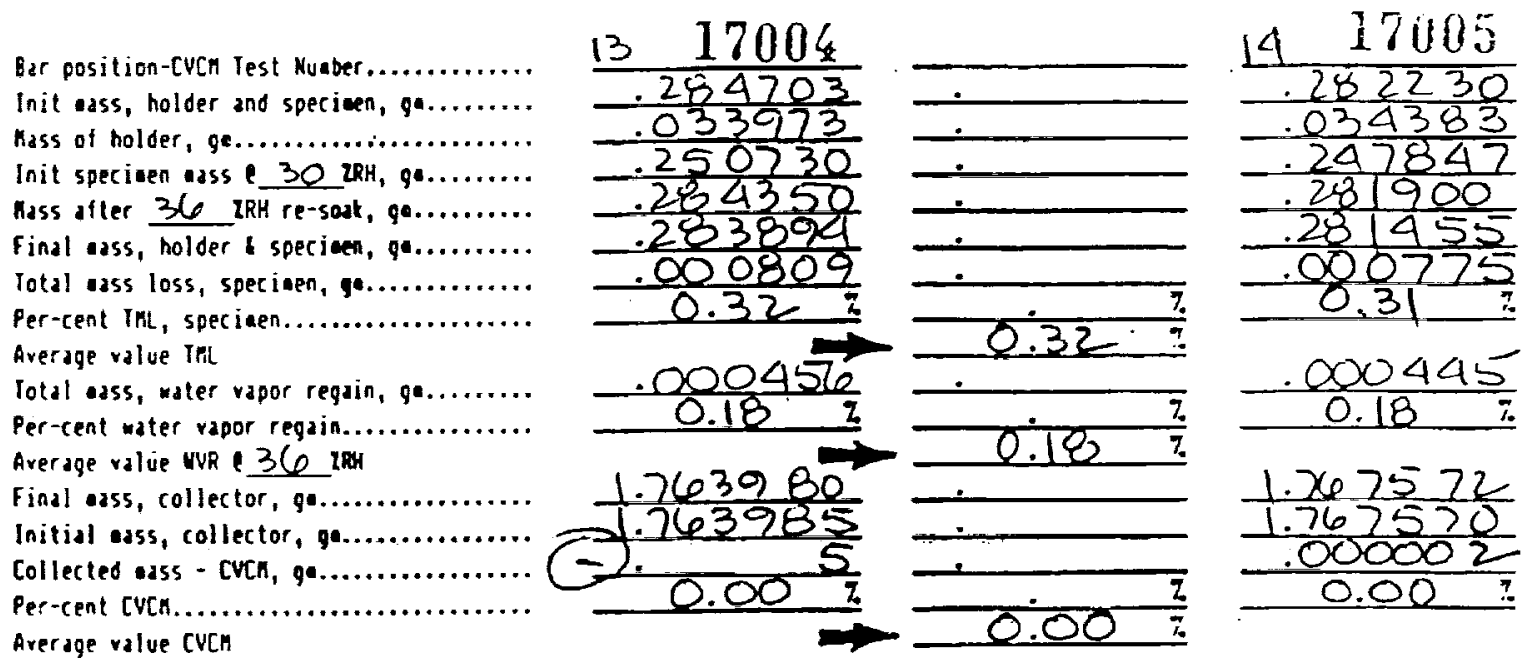

Average value WVR 36 200

Final azs, collector, ge.

Initial eass, collector,

Pee-cent cych.

Average value CVCH

Rearts: CVCn funmeighablel on separator plate to___ diaceter. CVCn appearance as follows: on collector plates: thin: heary: color:

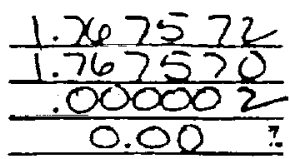
splotchy: Iringes: loggr: partially opaque: atie: transparent:

Xis not detectable soooth: sooky: excess: Deposit covers colored liquir: distorts eye reflection: clear liquid: I of collector discs:

Specisen appearance after test: no visible change

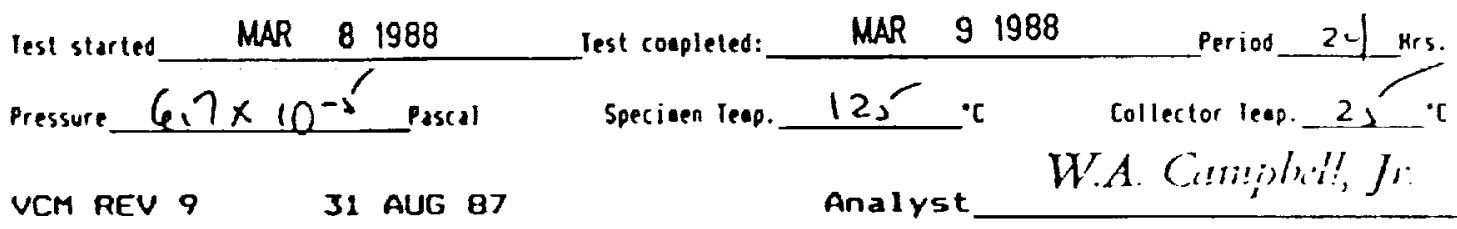

A-2. Retest of Sample 4, 985B-626 (\#17004). 
MICRO VCM TEST REQUEST AND DATA SHEET

(Requestor please read, then furnish all inforation above asterisks.)

Requested by Silaldane phone Date 2-5-86

Material Identification (product naee, nuaber, description, classitication, etc)

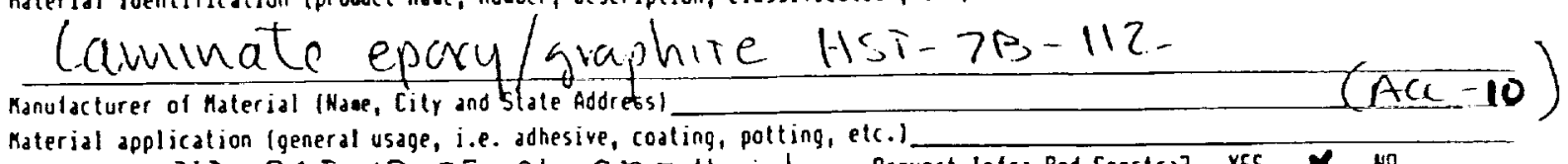

J. 0 . Huber $313-845-17-0 \overline{3}-\mathrm{Cl} \mathrm{CiB}=$ MaIil Request Infra-Red Spectra? YES_K_ HO

Indicate here all processing required by $65 F C$ katerials personnel. Include the recipe, curelsl, and special instructions to be perforaed.

If aterial is to be tested in the "as received" condition, without further processing required, indicale in full, past history, recipe, cure(s), post cure(s), nocenclature of coaponents, etc.

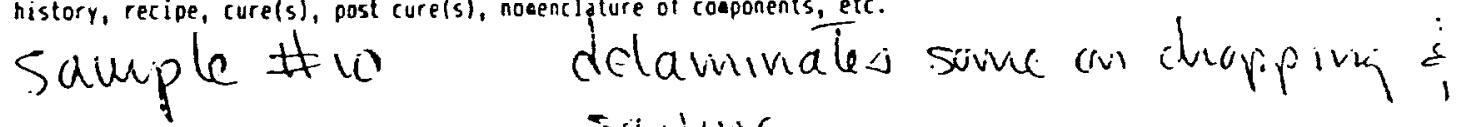
Salling

******************************************

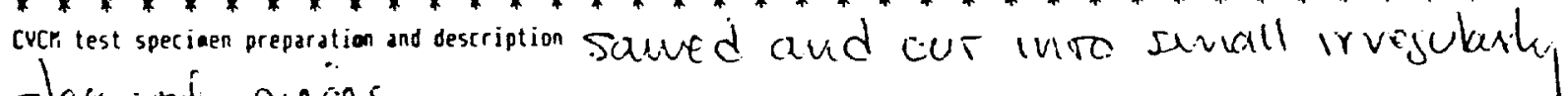
sha jipd puces.

Bar position-CVCn Test Nunber...............

Init eass, holder and specien, ga.........

nass of holder, ga.......................

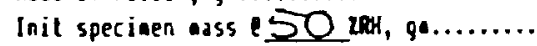

hass after 50 zRH re-soat, qa..........

Final esss, holder I specieta, ga..........

Total eass loss, specieen, a..............

Per-cent ThL, specieen....................

Averaģe value ITl

Total eass, water vapor regain, ge.........

Per-cent water vapor regain.................

Average value WVR $5 \mathcal{O}$ IRH

Final ass, collector, gn..................

Initial odss, collector, qu................

Collected ass - cuch, ga.................

Per-cent CUCH............................

Average value CUCA
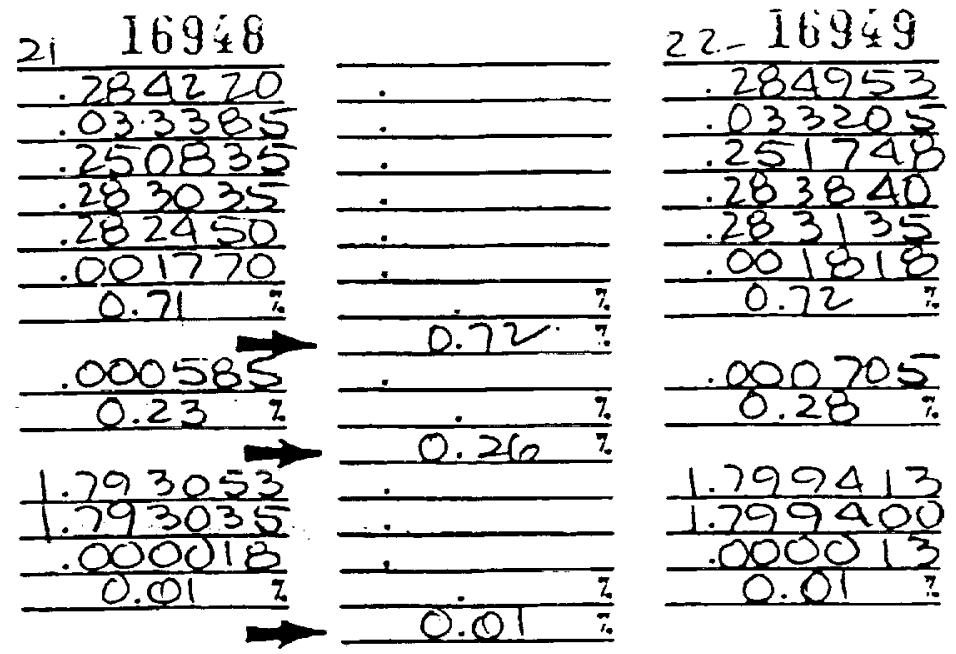

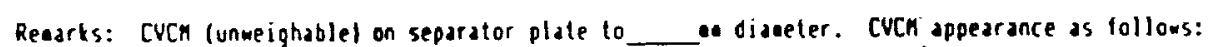
on collector plates: exrremely thin: splotchy: partially quaque: heary: blue_color: opaque: _uatle: transparent: is not detectable

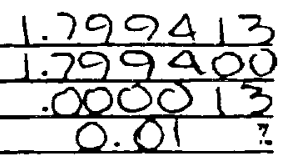
fringes: loggr: colored liquid: distorts eye reflection: _clear liquid: ercess: Deposit cavers_ $\Omega-10$ i of collector discs: bavely de recrable sperieen appearance after test: no visible change

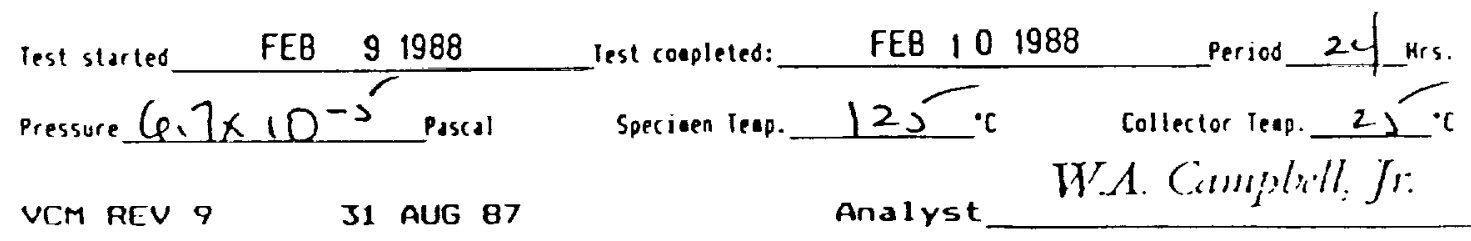

A-3. Sample 10, HST-7B-112 (\#16948). 
ORIGINAL PAGE IS
MICRO VCM TEST REQUEST AND DATA SHEET OF POOR QUALITY
(Requestor please read, then furnist all inforeation above asterisks.)

Requested by Sclaldone

Sclaldave phone

Date

Material Identification (product nace, nuber, description, classitication, etc)

Laminate epory/graphure HST-7B-112

Manufacturer of Katerial (Hace, City and State Address).

haterial application lgeneral usage, i.e. adhesive, coating, potting, etc.) - Cavulnato

J. 0 . Nuber $313-473-10-06-01$ Space Sic

Indicate here all processing required by 6SfC haterials personnel. Include the recipe, cure(s), and special instructions

to be perforeed.

$$
\begin{aligned}
& \begin{array}{l}
\text { Revinet asc leque } \\
\text { nui Feta Depheates }
\end{array} \\
& \text { pisitions } 21 \dot{2 z}
\end{aligned}
$$

If aterial is to be lestet in the as received" condition, without further processing required, indicate in full, past nistory, recipe, cure(s), past curelsl, nocenclature of coeponents, etc.

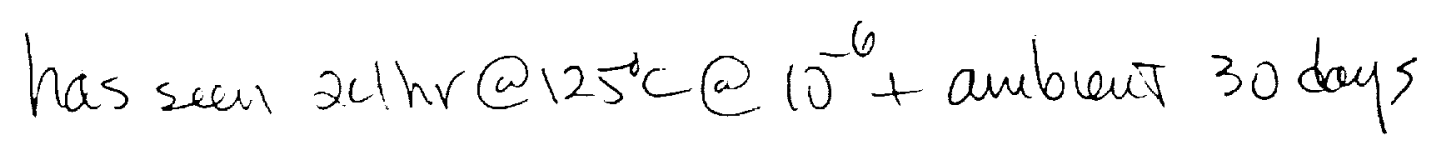

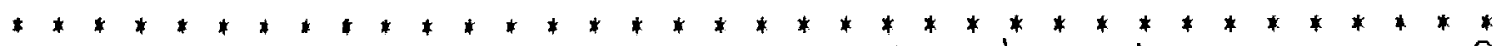
inch test speciaen preparation and description small irregularly shaped peces placed
in bociss

Bdr position-Cuir test hueter..............

Init iass, holder and speticen, ga.........

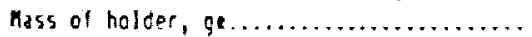

Init specinen ass 30 zRH, $9 . \ldots . . .$.

hass atter 36 zRH re-sod, ge..........

Final eass, holder I spectere, ca.........

Total eass loss, speriepr, ge..............

Per-cent Ihi, spectien.....................

Averagge value tri

Total adss, mater vaprar tegali, ga........

Per-cent waler vapor reŗain.................

Grerage value wiv 35 IPH

Final eas5, collector, ge.................

Initial ass, collector, 9 a................

Collected ass: - cucr, ge.................

Per-cent crer..........................

Arerage value cuch
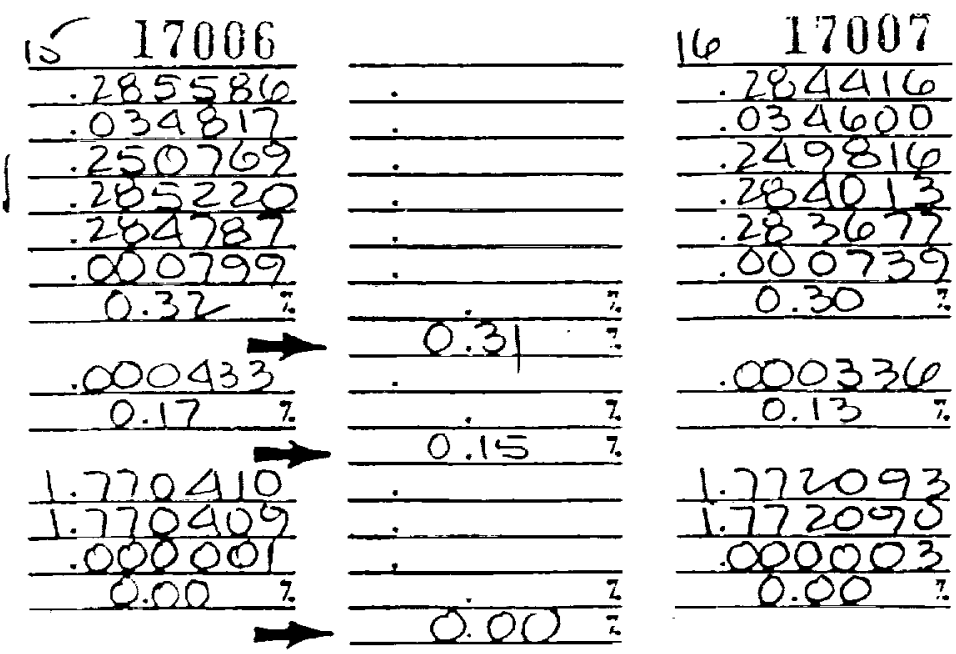

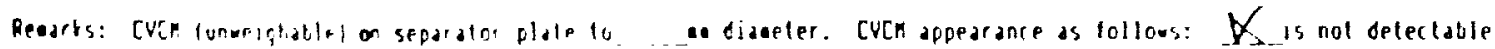
on collector plates: .

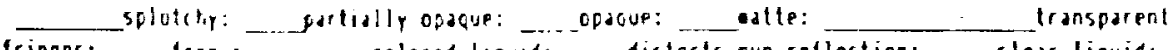
color: seootit: sooky: fringes: _laggy: _...... colored liquide _.. distorls eye rellection: clear liquid:

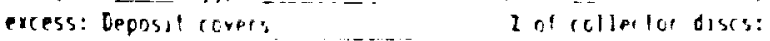

Specien apparance fiter lest: no visible chambe

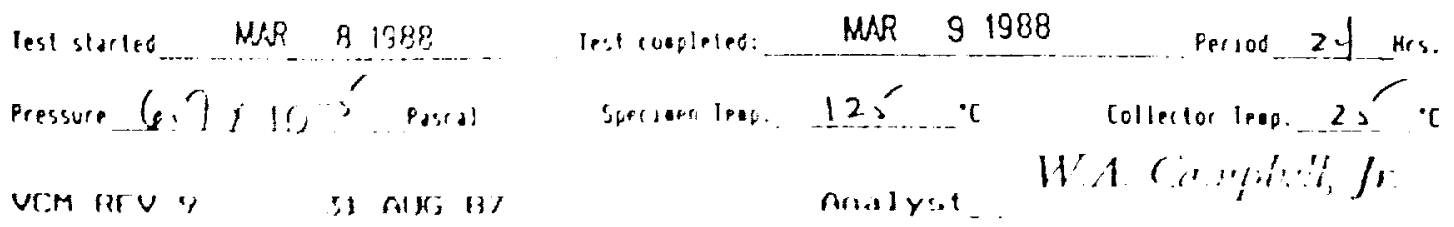

1-4. Retest of Simple 10, IIST-713-112 (\#17006). 


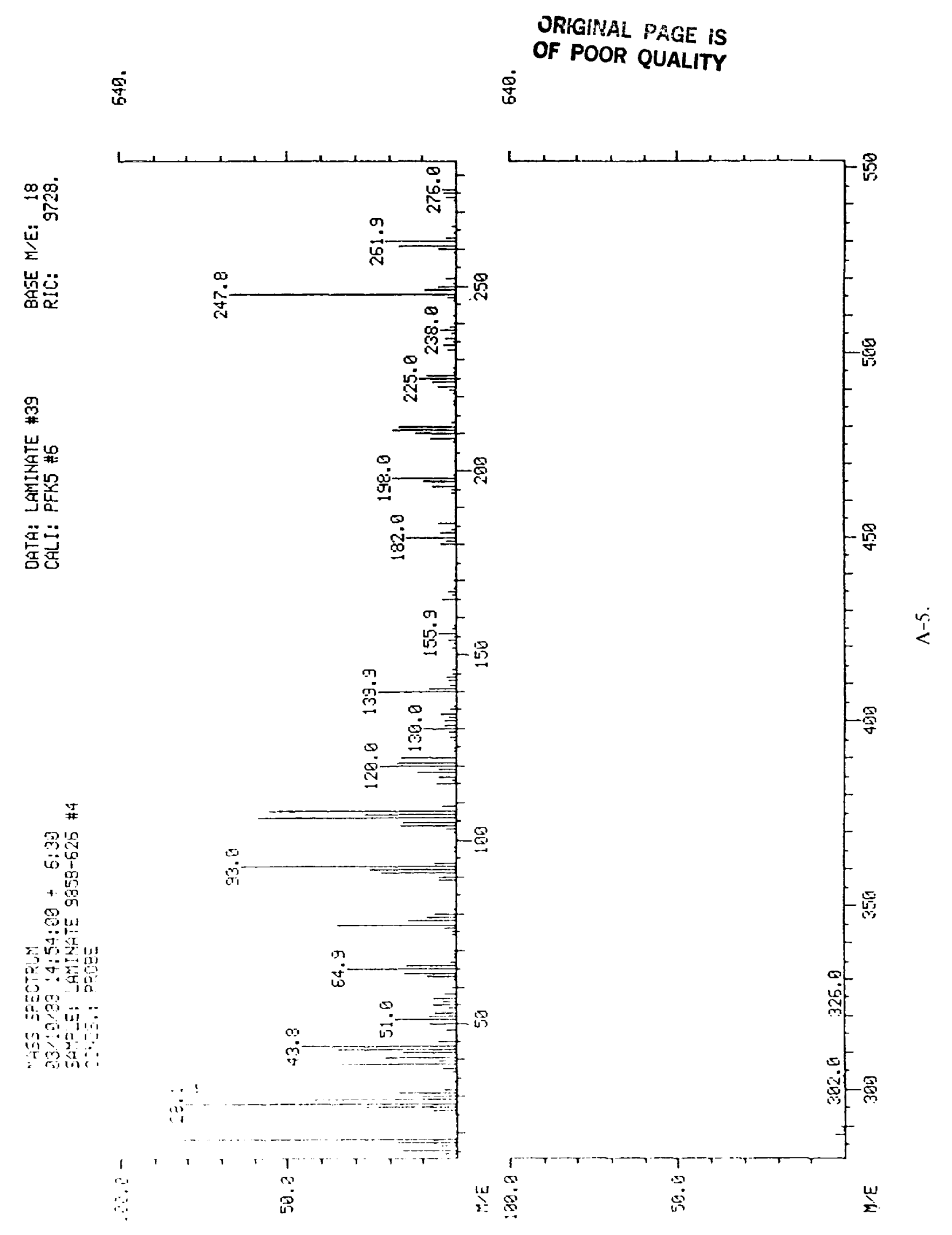




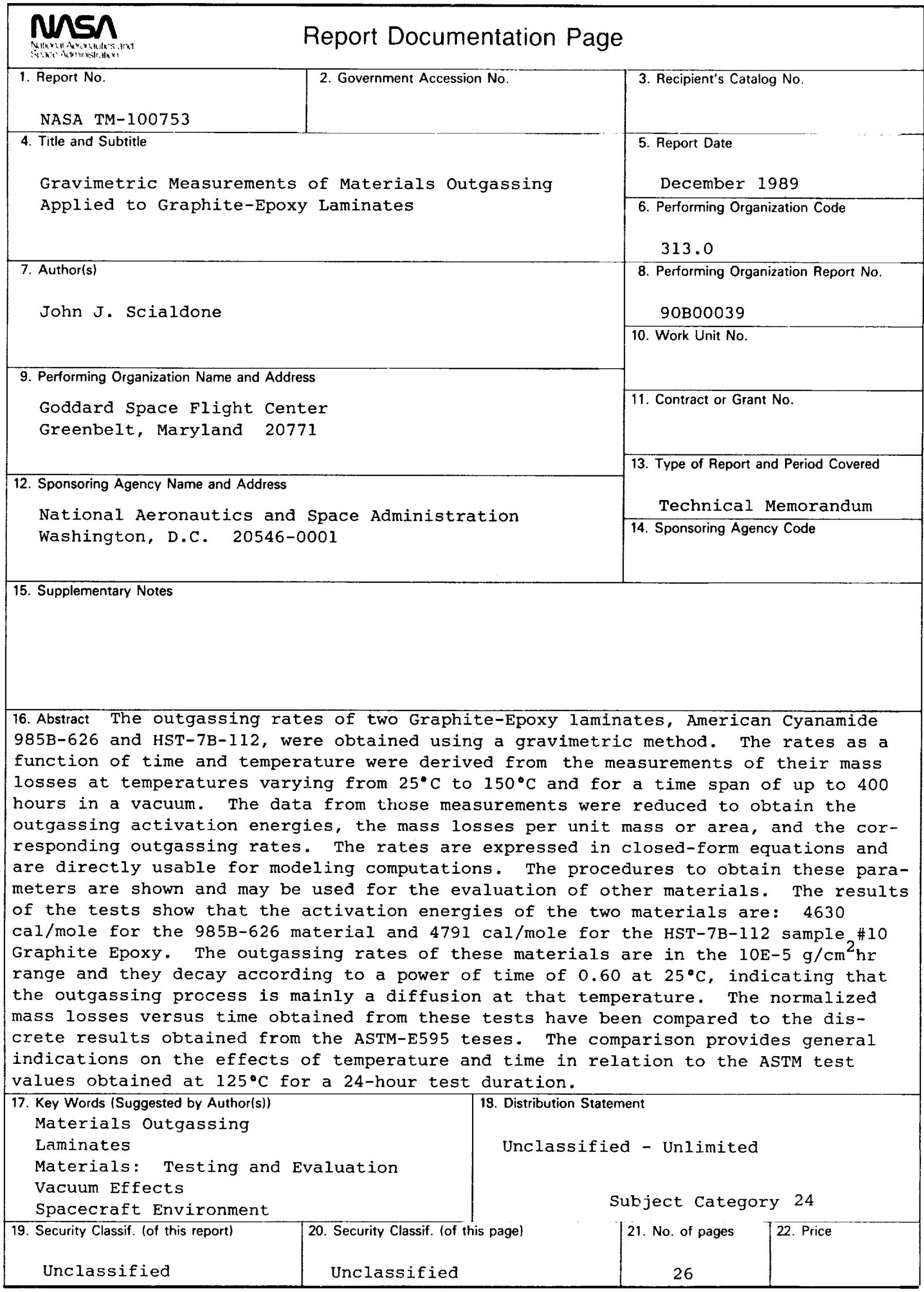


